\title{
Cell- and promoter-specific activation of transcription by DNA replication
}

\author{
David S. Grass, ${ }^{1}$ Douglas Read, E. Diann Lewis, ${ }^{2}$ and James L. Manley \\ Department of Biological Sciences, Columbia University, New York, New York 10027 USA
}

\begin{abstract}
To study the effects that DNA replication can exert on transcription in mammalian cells, we have analyzed transient expression from the adenovirus major late promoter contained on replicating and nonreplicating plasmids in several cell types. When a 100-bp fragment containing the late promoter was used to direct expression of the simian virus 40 (SV40) early region, efficient transcription could be detected that was only slightly enhanced when a functional origin of replication was included in the plasmid. In contrast with this, and with similar findings using related late promoter-containing plasmids, expression from this promoter was absolutely dependent on DNA replication when it was inserted in the region of SV40 DNA encoding the late mRNA $5^{\prime}$ ends and expression was assayed in human HeLa cells and BSC-1 and COS-7 monkey cells. In contrast, transcription was totally independent of replication in human 293 cells. These results, which were not due to differences in template copy number, suggest that both cis- and trans-acting factors can influence a promoter's response to DNA replication and point to possible functional similarities between replication origins and transcriptional enhancers.
\end{abstract}

[Key Words: Transcription; DNA replication; SV40]

Received June 15, 1987; revised version accepted October 6, 1987.

Gene expression in animal cells is controlled in large part by the action of sequence-specific DNA binding proteins that interact with transcriptional promoter and enhancer elements (for review, see McKnight and Tjian 1986). An interesting question, which has received only modest attention so far, is, how do changes in chromatin structure, such as those that may be brought about by DNA replication, affect transcriptional regulation? The potential of DNA replication to play a role in controlling gene expression may be important in a variety of instances, ranging from the ordered patterns of expression that occur during viral infections to the establishment and maintenance of differentiated states during development.

Viruses have provided valuable models that have led to the identification of the key mechanisms and pathways used in the control of gene expression in all animal cells. Strategies employing viral systems have also been useful in studying the influence of DNA replication on transcription. Most DNA viruses display dramatically different patterns of gene expression before and after DNA replication (for examples, see Tooze 1981). Although a part of the explanation for such phenomena may be that elevated expression of late genes simply reflects increases in template copy number, it is very likely that other factors are involved. For example,

'Present address: Memorial Sloan-Kettering Cancer Center, New York, New York 10021 USA.

2Present address: Department of Biological Sciences, Stanford University, Stanford, California 94305 USA. superinfection studies with adenovirus revealed that late gene expression from the superinfecting virus could not be detected early after superinfection, even though the initially infecting virus had already entered the late phase (Thomas and Mathews 1980). This type of study argued that it is not simply accumulation to high copy number of the DNA templates, or of early gene products, that is required for efficient late expression. Rather, it appears that the act of DNA replication per se brings about changes in the viral chromosome that allow late expression to commence. Analogous results were seen when late expression from a small DNA tumor virus, simian virus 40 (SV40), was studied by similar protocols (Thomas and Mathews 1980; M. Mathews, pers. comm.), again indicating that neither accumulation of an early gene product, in this case the viral large $T$ antigen, nor increased copy number is sufficient to catalyze maximal late gene expression. DNA replication can also repress viral transcription. Efficient expression of the SV40 early region in human 293 cells occurs only if DNA replication is blocked, either by mutation or by chemical inhibitors (Lewis and Manley 1985b; Lebkowski et al. 1985).

Little is known about precisely how viral DNA replication affects transcription. For example, the SV40 origin of replication and viral early and late promoters are overlapping. Thus, are the effects of replication on transcription due to the influence of the assembly of a DNA replication complex on nearby transcription initiation complexes? Or are these effects due to the movement of the replication fork through transcriptional control re- 
gions? Why does the response of different promoters to replication vary? Might the effects of replication on transcription be cell specific?

To begin to address these questions, we have studied expression from adenovirus and SV40 late promoters contained on replication-competent and -incompetent plasmids in different cell types. The cloned adenovirus major late promoter (Ad2MLP) is expressed efficiently in transient expression assays in a number of cell types when contained on nonreplicating plasmids, as long as an enhancer, such as the SV40 72-bp repeated element, is present in cis (Hen et al. 1982; Lewis and Manley 1985a). In contrast, the complex SV40 late promoter, which produces transcripts initiated at multiple sites within an approximately 300 -bp region, requires DNA replication to be utilized efficiently in all mammalian cell types studied to date (for reviews, see Tooze 1981; Fried and Prives 1986). Previously, we constructed an SV40 mutant, pSVAdL, in which a 100-bp fragment of adenovirus DNA containing all the sequences required for late promoter function was inserted in the SV40 late promoter region, downstream of the 72 -bp repeats. During the late phase of the infectious cycle in permissive monkey cells, i.e., following the onset of viral DNA replication, the Ad2MLP was utilized very efficiently, such that the majority of SV40 late transcripts initiated at the authentic Ad2MLP start site/Grass and Manley 1986). Here we describe experiments that examine the influence of DNA replication on transcription from the Ad2MLP in pSVAdL and several related plasmids.

\section{Results}

We previously observed that the adenovirus 2 major late promoter in the plasmid pSVAdL was inactive following transfection of permissive monkey kidney cells when DNA replication was blocked by addition of cytosine arabinoside to the culture medium (Grass and Manley 1986). This finding was somewhat unanticipated, because a number of previous experiments (see e.g., Moreau et al. 1981; Grinnel et al. 1986) had shown that the Ad2MLP functions efficiently in several cell types, including monkey kidney, independently of DNA replication, provided it is linked to an enhancer, as is the case in pSVAdL. To investigate this inhibition further, an origin-of-replication-defective variant of pSVAdL (pSVAdLori $^{-}$| was constructed by creating a 3-bp deletion at the $B g l$ restriction site in the viral sequences of pSVAdL. In addition, pSVAdL' and pSVAdLori ${ }^{-\prime}$ were constructed by inserting the viral sequences of pSVAdL and pSVAdLori- $^{-}$, respectively, into the plasmid vector pSVOd, which contains the SV40 origin of replication (SV40 nucleotide 5171-160|. Figure 1 and Materials and methods give details of the plasmid constructions.

\section{Expression from the Ad2MLP is affected differentially by DNA replication in HeLa and 293 cells}

We chose to study the possible link between DNA replication and transcription in HeLa and 293 cells because these cell lines are known to express high levels of RNA

A

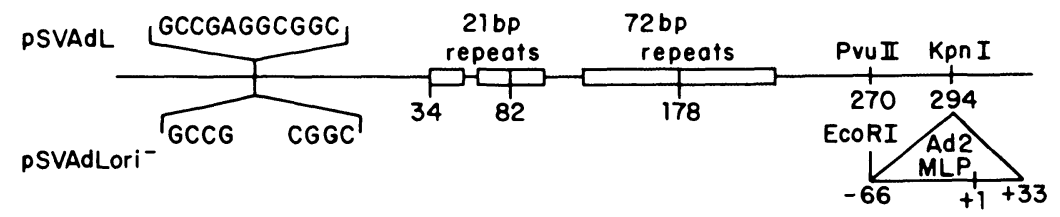

B
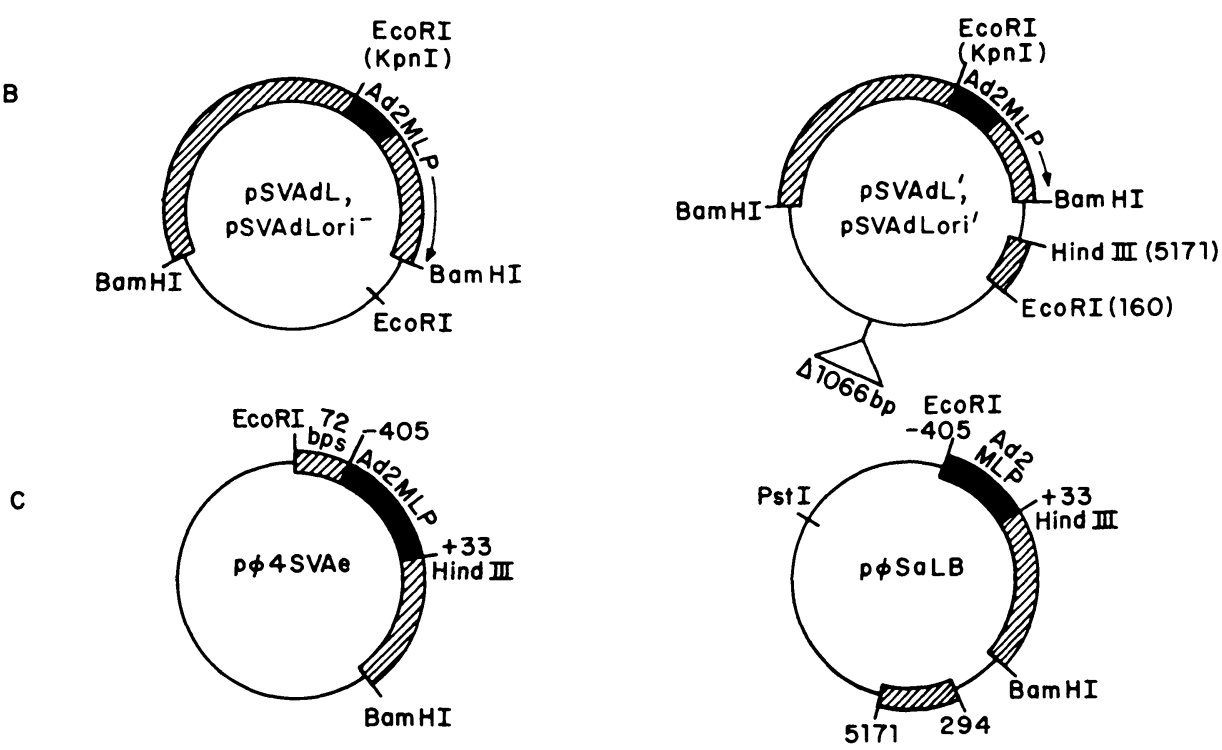

Figure 1. Schematic diagram of SV40-adenovirus recombinant plasmids. (A) Structure of the promoter-origin region of pSVAdL and pSVAdLori- ${ }^{-}$showing the position of the Ad2 DNA insert and the sequence at the wild-type SV40 BglI cleavage site. $(B)$ Structure and orientation of pSVAdL, pSVAdLori ${ }^{-}$, pSVAdL $^{\prime}$, and pSVAdLori ${ }^{-}$. Early and late regions of SV40 are labeled. (C) p $\phi 4 S V A e$ and p $\phi S a l B$. Thick lines denote adenovirus sequences, hatched lines SV40 sequences, and solid lines pBR322 sequences. 
from the Ad2MLP in transient expression assays (see e.g., Lewis and Manley 1985a). In addition, both cell lines, especially 293 cells, which are a human embryonic kidney cell line transformed by the Ela plus Elb region of adenovirus 5 (Graham et al. 1977; Aiello et al. 1979), are capable of replicating SV40-origin-containing plasmids in the presence of the viral large $\mathrm{T}$ antigen (Lebkowski et al. 1985; Lewis and Manley 1985b). To determine whether transcription initiating from the Ad2MLP in pSVAdL and its derivatives could be detected, HeLa and 293 cells were transfected with pSVAdL, pSVAdLori ${ }^{-}$, pSVAdL' - , or pSVAdLori ${ }^{-1}$. Cytoplasmic RNA was isolated $48 \mathrm{hr}$ post-transfection and nuclease S1 analysis was performed using a BstNI $5^{\prime}$ end-labeled probe (labeled at SV40 nucleotide 358). Ad2MLP expression was readily detected in pSVAdLtransfected HeLa cells, but was totally absent when the same cells were transfected with pSVAdLori- (Fig. 2A, lanes $a$ and $b /$, suggesting that the activity of the Ad2MLP in these plasmids was dependent on DNA replication. Expression in HeLa cells from the Ad2MLP in pSVAdLori ${ }^{-}$has never been detected, even after autoradiographic exposures considerably longer than the one shown. Figure $2 \mathrm{~A}$ also shows that the Ad2MLPs in pSVAdL ${ }^{\prime}$ and pSVAdLori ${ }^{-1}$, which each contain functional replication origins at distal sites, were active in HeLa cells (lanes $\mathrm{c}$ and d). This finding supports the idea that the lack of expression in pSVAdLori ${ }^{-}$was due to a lack of DNA replication and not to a direct effect on transcription of the 3-bp deletion at the BglI site. In sharp contrast, when expression in 293 cells was examined, the Ad2MLP was found to be equally active in both pSVAdL and pSVAdLori ${ }^{-}$(Fig. 2B, lanes $a$ and b), suggesting that expression of the Ad2MLP in these cells was not only independent of DNA replication, but was unaffected by it. The Ad2MLP in both pSVAdL' and pSVAdLori $^{-1}$ was also active in these cells (Fig. 2B, lanes c and d).

\section{Replication and early gene expression in transfected cells}

We next wished to know whether the observed differences in expression simply reflected differences in template copy number. To determine how much SV40 DNA was present in the nuclei of the transfected cells and to verify that the origin mutation did in fact prevent replication, Southern blot analysis (Southern 1975) was performed on DNA isolated from transfected HeLa and 293 cell nuclei. DNA preparations were digested with SalI to linearize the DNA, and also with either no additional enzyme, with $D p n I$, or with $M b o I$. Samples were then separated on a $1 \%$ agarose gel and transferred to nitrocellulose. Because DpnI will digest only DNA that is methylated at the adenosine residue in its recognition

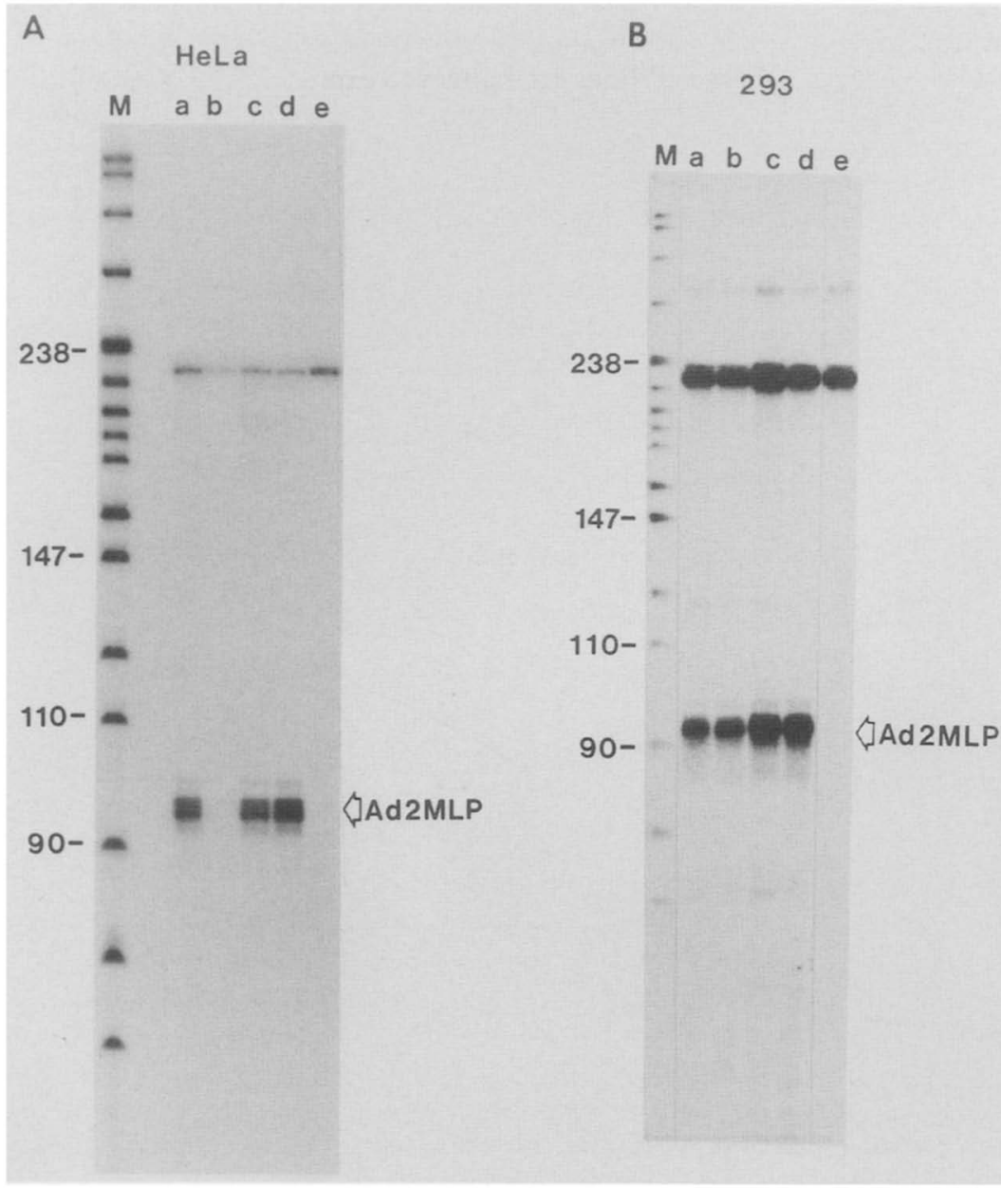

Figure 2. Analysis of Ad2MLP expression in transfected HeLa $(A)$ and $293(B)$ cells. S1 nuclease analysis of cytoplasmic RNA isolated from either HeLa or 293 cells transfected with pSVAdL (a), pSVAdLori- ${ }^{-}(b)$ pSVAdL' $^{\prime}(c)$, pSVAdLori ${ }^{-\prime}(d)$, or no DNA $(e)$ after hybridization with a single stranded BstNI fragment isolated from pSVAdL covering SV40 nucleotides 232-358 and labeled at the $5^{\prime}$ end (nucleotide 358 ). Following digestion with S1 nuclease, protected fragments were resolved by electrophoresis through a $5 \%$ polyacrylamide $-8 \mathrm{M}$ urea gel. Marker (M) was a HpaII digest of pBR322. Numbers indicate sizes in nucleotides. The band of approximately 230 nucleotides represents undigested probe. 
sequence, sensitive DNA grown in $d_{a m}{ }^{+}$bacteria becomes resistant to the enzyme if it has replicated in the transfected mammalian cell. In contrast, $M b o I$ will digest only replicated DNA, because this enzyme does not cleave dam-methylated DNA.

Figure 3 shows the results obtained following hybridization of the filter-bound DNA with a nick-translated SV40 DNA probe. Both MboI and DpnI assays revealed significant replication of pSVAdL DNA in both HeLa and 293 cells, whereas as expected, replication of pSVAdLori ${ }^{-}$DNA could not be detected. pSVAdL' and pSVAdLori ${ }^{-1}$ both replicated to approximately the same extent as pSVAdL (results not shown). Quantitation of the total amount of DNA in the transfected cells by densitometric scanning of autoradiograms similar to that shown in Figure 3 revealed that approximately fivefold more pSVAdL DNA accumulated in the nuclei of the transfected cells than did pSVAdLori ${ }^{-}$DNA. Thus, the increase in template copy number brought about by DNA replication was relatively modest and was certainly insufficient to explain the all-or-nothing effect on Ad2MLP transcription observed in HeLa cells (Fig. 2). Rather, promoter activity in these cells correlates with the presence of replicated DNA.

293 cells have been reported to retain significantly more transfected DNA than other cell types (Alwine 1985). Although the data in Figure 3 argue that this was not the case in our studies (see also Discussion), we carried out an additional experiment to show that the DNA replication-independent expression of the Ad2MLP in 293 cells was not due simply to a higher template copy number. Specifically, 293 and HeLa cells were transfected with pSVAdL or pSVAdLori ${ }^{-}$as above, except that the amount of specific DNA was reduced to $5 \%$ the amount used in the experiment shown in Figure 2. The results of nuclease S1 analysis (not shown) were exactly the same: No expression was detected in HeLa cells in the absence of DNA replication, whereas replication was without effect on the relatively high level of Ad2MLP transcription observed in 293 cells.

We have shown previously that mutations in SV40
DNA similar to the 3-bp deletion at the BgII site in pSVAdLori- ${ }^{-}$were without significant effect on viral early gene expression in HeLa cells (Lewis and Manley 1985b). Because this mutation resulted in such a dramatic effect on Ad2MLP expression in pSVAdL, we wished to ascertain that it had not totally inactivated pSVAdL as a transcriptional template. To this end, early gene expression in HeLa cells transfected with pSVAdL, pSVAdLori ${ }^{-}$, pSVAdL' $^{\prime}$, or pSVAdLori ${ }^{-\prime}$ was assayed by indirect immunofluorescent measurements of viral $\mathrm{T}$ antigen. Cells were fixed $48 \mathrm{hr}$ post-transfection and treated with the anti- $\mathrm{T}$-antigen monoclonal antibody 416 (Crawford et al. 1982), followed by treatment with fluorescein-conjugated goat anti-mouse antisera. Quantitation of the percentages of T-antigen-positive cells (Table 1) revealed relatively efficient early gene expression in cells transfected with each of the four plasmids. Thus, the 3-bp deletion in pSVAdLori ${ }^{-}$, although totally abolishing expression from the Ad2MLP and DNA replication, had little, if any, effect on SV40 early gene expression in HeLa cells.

\section{The replication requirement for Ad2MLP expression does not exist in other plasmids}

As mentioned above, the cloned Ad2MLP has been shown to be expressed efficiently in HeLa cells in the absence of DNA replication, provided an enhancer was contained in the recombinant plasmid. For example, expression from the plasmid $p \phi 4 S V A e$, which contains the Ad2MLP fused to the SV40 early region, was detected in HeLa cells as long as the SV40 enhancer was present in the plasmid (Lewis and Manley 1985a). Since this plasmid contains no origin of DNA replication, the observed Ad2MLP expression in HeLa cells did not require DNA replication as it does in PSVAdL-transfected HeLa cells. At least two explanations for this apparent discrepancy can be put forth. First, a plasmid such as p $\phi 4 S V A e$, which can give rise to Ad2MLP transcription in the absence of DNA replication, might show a dramatic increase in expression if allowed to replicate, as seen with

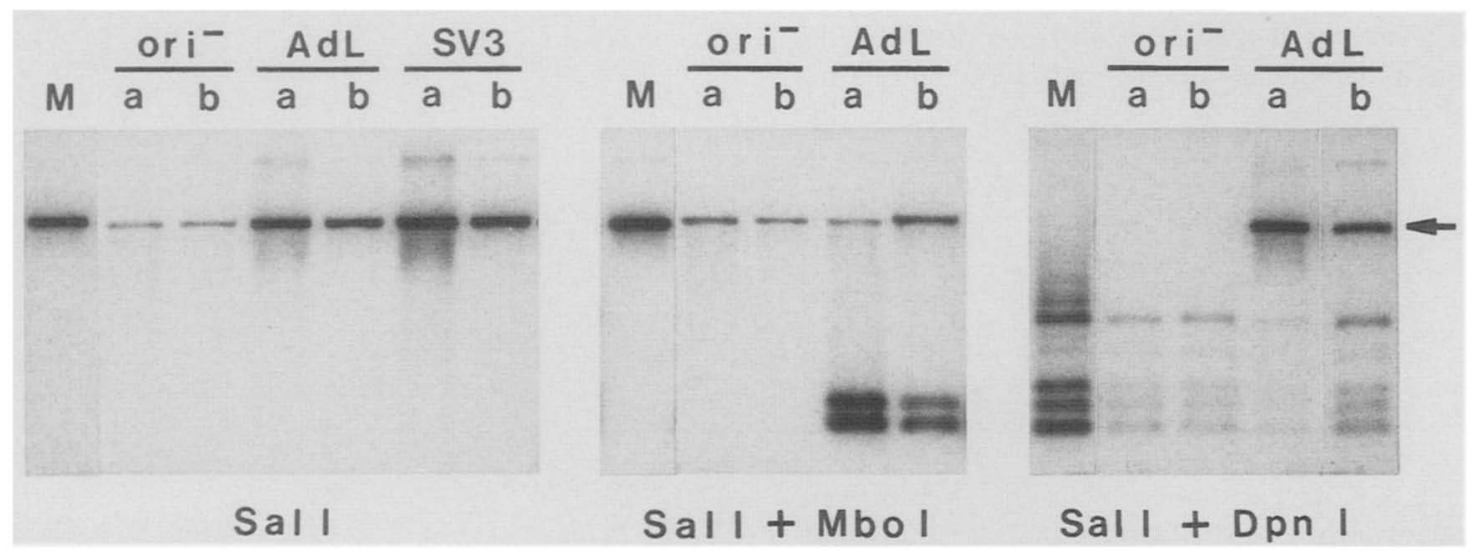

Figure 3. Replication of recombinant plasmids in transfected 293 and HeLa cells. Southern blot analysis of low-molecular-weight DNA isolated from $293(a)$ or HeLa $(b)$ cells transfected with pSVAdLori ${ }^{-}$(ori ${ }^{-}$), pSVAdL (AdL), or pSV3 (SV3). Samples (5\% of total isolated) were treated with the restriction enzymes indicated and subjected to electrophoresis through a $1 \%$ agarose gel. Lanes marked $M$ represent $5 \mathrm{ng}$ of pSVAdL DNA isolated directly from $E$. coli. The arrow indicates full-length Sall linearized DNA. 
Table 1. Expression of $T$ antigen in transfected HeLa cells

\begin{tabular}{lc}
\hline Plasmid & $\begin{array}{l}\text { Percentage of cells expressing } \\
\text { T antigen }\end{array}$ \\
\hline pSVAdL & 14.6 \\
pSVAdLori ${ }^{-}$ & 17.9 \\
pSVAdL $^{\prime}$ & 13.7 \\
pSVAdLori $^{-1}$ & 17.4 \\
\hline
\end{tabular}

Indirect immunofluorescence was carried out as described (Verderame et al. 1980) on cells harvested $40-48 \mathrm{hr}$ post-transfection. The number of T-positive cells for each plasmid is expressed as a percentage of total cells counted.

pSVAdL. Second, the DNA context in which the promoter (or enhancer) is contained might affect its response to DNA replication. That is, the SV40 late promoter sequences in which the Ad2MLP is embedded in pSVAdL, or the sequences adjacent to the enhancer, might impart upon the Ad2MLP a requirement for DNA replication.

To distinguish between these possibilities, we examined the effect of DNA replication on transcription from pф4SVAe (Lewis and Manley 1985a). This was accomplished by determining the levels of transcription from $\mathrm{p} \phi 4 \mathrm{SVAe}$ and $\mathrm{p} \phi \mathrm{SaLB}$, a replication-competent plasmid similar to p $\phi 4$ SVAe. [See Fig. 1 and Materials and methods. Although the SV40 enhancer is located in different positions in the two plasmids, this was shown previously (Yu and Manley 1986; unpubl. results) not to affect its ability to enhance Ad2MLP expression.] Following transfection of HeLa cells and extraction of cytoplasmic RNA, transcripts that had initiated from the Ad2MLP were detected by primer extension analysis (Fig. 4). As previously observed (Lewis and Manley 1985a), p $\phi 4$ SVAe-transfected cells produced significant quantities of RNA initiated from the Ad2MLP. The amount of SV40-specific RNA synthesized in p $\phi$ SaLBtransfected cells was approximately fourfold greater than that detected in cells expressing p $\phi 4$ SVAe. This difference in transcription is significantly less than the greater than 100-fold difference between pSVAdL and pSVAdLori- (see Fig. 2), indicating that DNA replication only slightly increased transcription from the Ad2MLP in p $\phi 4 S V A e$. This was not due to inefficient replication of $\mathrm{p} \phi \mathrm{SaLB}$ because Southern blot analysis indicated that the efficiency with which this plasmid replicated was similar to that of pSVAdL (results not shown). These results further support the idea that the dramatic difference observed in Ad2MLP expression between pSVAdL and pSAVdLori ${ }^{-}$was not due solely to changes in template number. Rather, it appears that the nucleotide sequences surrounding the Ad2MLP-enhancer in pSVAdL in some way impart replication dependence on this promoter-enhancer combination. Results similar to those shown in Figure 4 were obtained when $p \phi 4$ SVAe and $p \phi$ SaLB were transfected into 293 cells (data not shown).

The Ad2MLP in pSVAdLori- is inactive in COS-7 monkey cells

SV40 large $\mathrm{T}$ antigen can activate transcription from several promoters (Brady et al. 1984a; Keller and Alwine 1984; Alwine 1985; Robbins et al. 1986). The SV40 late promoter itself was the first identified example of this phenomenon: $\mathrm{T}$ antigen is required to obtain detectable levels of late gene expression in the absence of viral DNA replication (Brady et al. 1984a; Keller and Alwine 1984). The cis-acting sequences important for this activation are the minimal SV40 origin of replication ( $T$ antigen binding site II) and the 72-bp repeats (Hartzell et al. 1984b; Brady and Khoury 1985; Keller and Alwine 1985).

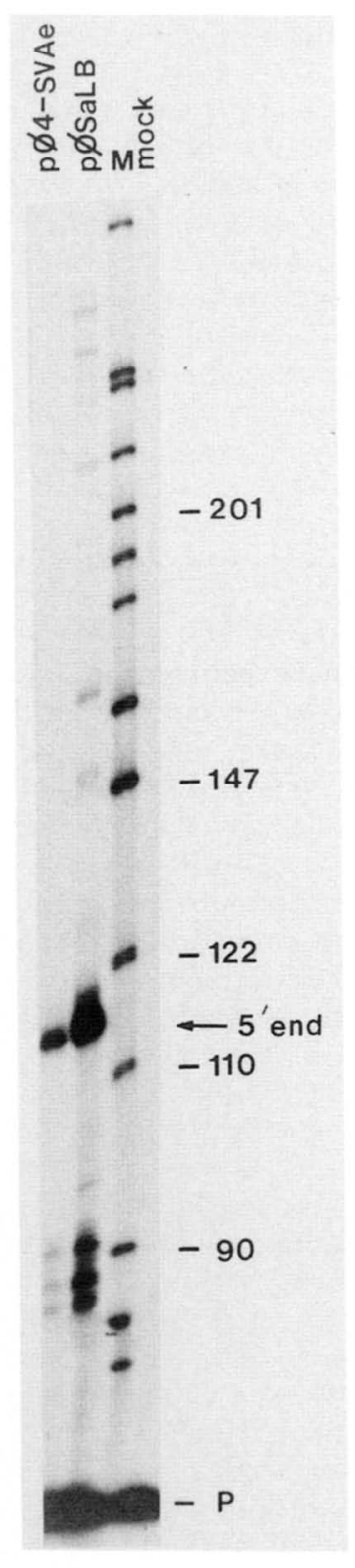

Figure 4. Effect of replication on the expression of the Ad2MLP in p $\phi 4$ SVAe. Primer extension analysis of cytoplasmic RNA extracted from HeLa cells transfected with p $\phi 4 S V A e, p \phi$ SaLB, or no DNA (mock). A primer complementary to SV40 nucleotides 5131-5094 was labeled at its $5^{\prime}$ end, hybridized to RNA samples, and elongated with ALV reverse transcriptase. Primer extension and gel electrophoresis conditions were as described in Materials and methods. P represents the position of unextended primer. 
Because the levels of $\mathrm{T}$ antigen in cells transfected with pSVAdL and its derivatives may be low /Grass and Manley 1986), we decided to test whether Ad2MLP expression from pSVAdLori ${ }^{-}$could be detected in the presence of higher levels of $\mathrm{T}$ antigen than would be produced in pSVAdLori ${ }^{-}$-transfected HeLa cells. To this end, the four pSVAdL-derived plasmids utilized in the above experiments were transfected into COS-7 monkey cells, which are SV40-transformed CV-1 cells that constitutively express $T$ antigen (Gluzman 1981). Cytoplasmic RNA was isolated $48 \mathrm{hr}$ post-transfection, and S1 nuclease analysis was performed as in the experiment shown in Figure 2. The results (Fig. 5) indicate that, as in HeLa cells, no expression from the Ad2MLP could be detected in pSVAdLori--transfected COS-7 cells, although high levels of expression from the other three plasmids were observed. We conclude that $\mathrm{T}$ antigen cannot stimulate transcription from the Ad2MLP in pSVAdLori ${ }^{-}$and that DNA replication is absolutely required for expression in this cell line as it is in HeLa cells. Virtually identical results were obtained when these plasmids were transfected into another monkey kidney cell line, BSC-1, which does not express endogenous $\mathrm{T}$ antigen (results not shown).

\section{Replication affects utilization of SV40 late initiation sites differentially in several cell types}

We showed previously that, in addition to the Ad2MLP, all of the SV40 late start sites were utilized in pSVAdLtransfected monkey cells, albeit at reduced levels (Grass and Manley 1986). These include the major SV40 late start site (nucleotide 325), which lies downstream of the Ad2MLP insert, as well as numerous less abundant upstream sites that extend into and even beyond the 72-bp repeats. To determine the role that replication might play in controlling initiation from these upstream heterogeneous starts, and whether that role varies in different cell types, pSVAdL and the related ori- derivatives were used to transfect HeLa, 293, or COS-7 cells. RNA was extracted and analyzed by $S 1$ nuclease analysis, using a probe chosen to detect upstream initiation sites (Fig. 6). For the most part, the results obtained mimic those observed when transcription from the Ad2MLP was assayed (see Figs. 2 and 5): Replication was required for expression from these start sites to occur in HeLa and COS-7 cells, but was without significant effect in 293 cells. However, at least two small differences are noteworthy. First, although replication was absolutely required for expression from all start sites in COS-7 cells, low levels of a number of the very minor initiations could be detected in pSVAdLori ${ }^{-}$-transfected HeLa cells (Fig. 6, lane b). Second, the distal origin present in pSVAdLori ${ }^{-\prime}$ (Fig. 6, lane d) was not as efficient at activating these upstream SV40 starts as it was for the more downstream Ad2MLP. This may indicate that the 3-bp deletion in pSVAdLori $^{-}$disrupts sequences that are required directly for initiation from these start sites. Additionally, the data show that the pattern of initiation sites used in the human cell lines, expecially 293, was

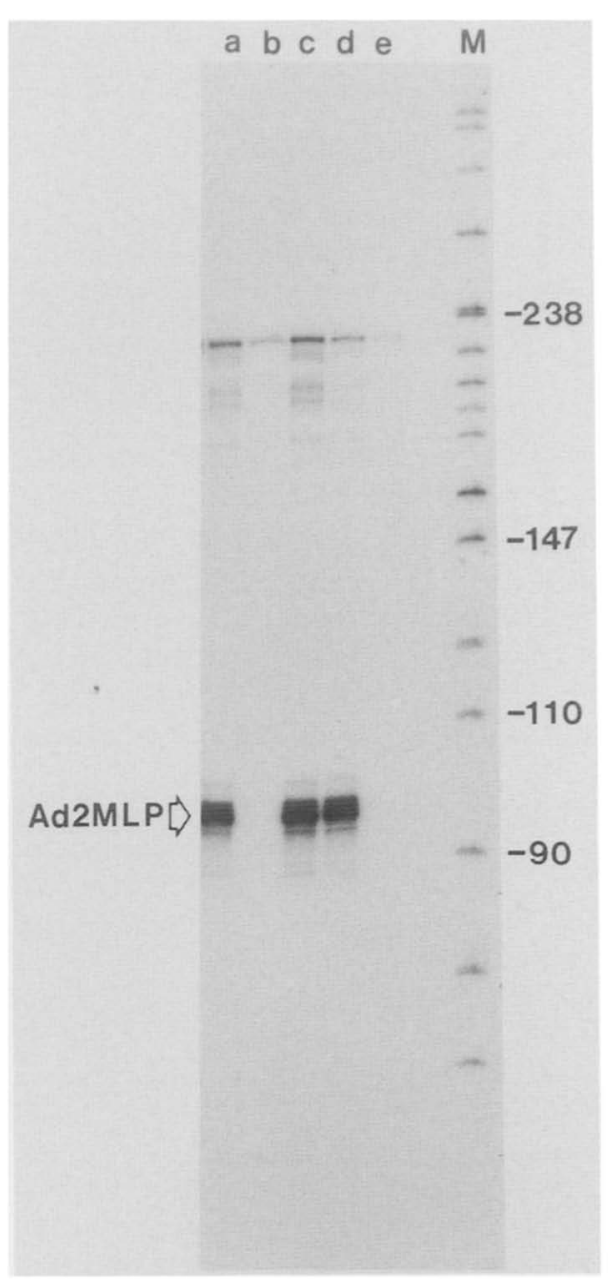

Figure 5. Replication-dependent expression of the Ad2MLP in pSVAdL in COS-7 monkey cells. S1 nuclease analysis of RNA isolated from COS-7 cells transfected with pSVAdL $(a)$, pSVAdLori- $^{-}(b)$, pSVAdL' $(c)$, pSVAdLori-' $(d)$, or no DNA $(e)$. RNA samples were hybridized to a strand-separated BstNI fragment extending from SV40 nucleotide 232 to 358 and labeled at its 5' end (nucleotide 358). Following S1 nuclease digestion, protected fragments were resolved by gel electrophoresis as in Fig. 2 .

significantly more heterogeneous than that in COS-7 cells. The cause for this increased heterogeneity is not clear.

\section{Discussion}

The experiments described here provide evidence that DNA replication can exert a strong and direct positive effect on promoter activity. Transcription in HeLa and COS-7 cells from the overlapping adenovirus and SV40 late promoters in the plasmid pSVAdL was completely inhibited by a 3-bp deletion in the SV40 origin of replication. That the mutation did not affect transcription directly was deduced from observations that transcription could be completely restored if a functional origin of replication was inserted elsewhere in the replication-defec- 


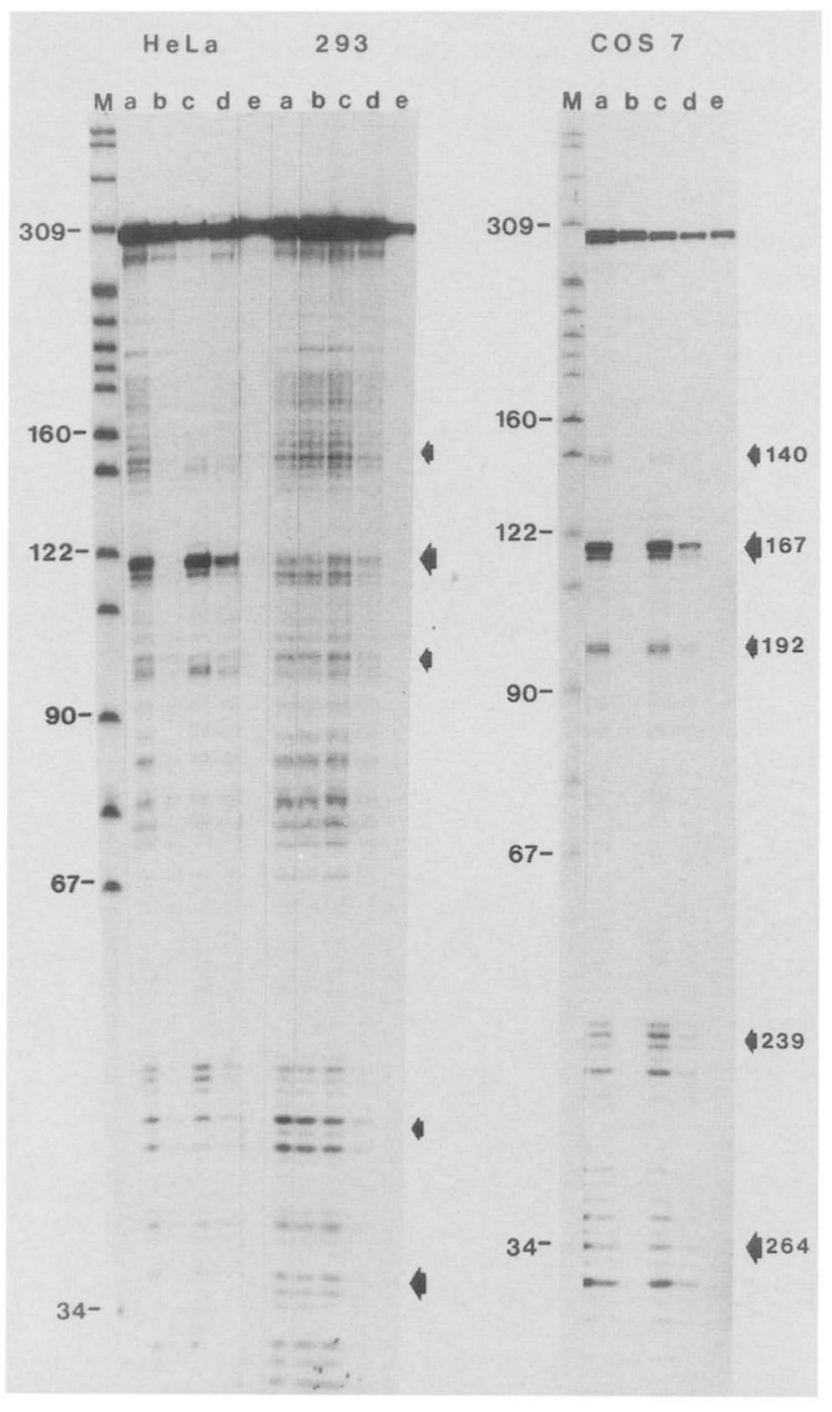

Figure 6. Effect of DNA replication on expression of the upstream SV40 late initiation sites. S1 nuclease analysis of RNA isolated from HeLa, 293, and COS-7 cells transfected with pSVAdL $(a)$, pSVAdLori ${ }^{-}(b), \operatorname{pSVAdL}^{\prime}(c), \operatorname{pSVAdLori}^{-1}(d)$, or no DNA $(e)$. The hybridization probe was a single-stranded DdeI fragment covering SV40 nucleotides 5228-287 and labeled at the 5' end (nucleotide 287). Gel electrophoresis conditions were as in Fig. 2. Arrows and SV40 coordinates on the right refer to positions of SV40 late transcription start sites used during infection monkey cells.

tive mutant. In addition, the observed transcriptional activation was not due simply to increased template copy number. On a per template basis, replicated molecules were, at a minimum, 20-fold more active than their nonreplicated counterparts.

The inhibition of SV40 late mRNA accumulation from the origin-defective mutants was not totally unexpected, because a number of previous studies have demonstrated a requirement of DNA replication for the synthesis of late mRNA or protein during SV40 infection of permissive monkey cells (for review, see Tooze 1981). However, the adenovirus late promoter has been shown previously to function effectively in transient expression assays similar to those described here in the absence of DNA replication (Hen et al. 1982; Lewis and Manley 1985a; Grinnell et al. 1986; Yu and Manley 1986). The two promoter elements are quite different and also require different protein factors in addition to RNA polymerase II to initiate transcription (see e.g., Davison et al. 1983; Dynan and Tjian 1983; Carthew et al. 1985; Sawadogo and Roeder 1985). Thus, it was somewhat surprising that the SV40 late promoter's requirement for DNA replication was found to be dominant over the adenovirus late promoter's lack of such a requirement.

What SV40 sequences impart replication dependence on the adenovirus late promoter? Two possibilities merit discussion. First, Brady and Khoury (1985) and Alwine and Picardi (1986) have presented evidence, in the form of in vivo competition assays, that a repressor-type molecule binds specifically to SV40 late DNA sequences. These results suggest the existence of factors that negatively regulate late transcription in the absence of DNA replication. Such a repression, which could block either transcription initiation or elongation (i.e., attenuation), might inhibit transcription from both promoters indiscriminately. An alternative notion is that transcription from the adjacent but oppositely orientated SV40 early promoter interferes with SV40 late transcription in the absence of DNA replication. Sequences within both the enhancer element and the GC-rich 21-bp repeats appear to be required for both early and late transcription (Fromm and Berg 1982; Hansen and Sharp 1983; Brady et al. 1984b; Hartzell et al. 1984a; Mishoe et al. 1984; Gidoni et al. 1985), and sequences located even further in the early direction, contained within $\mathrm{T}$ antigen binding site II and the origin of DNA replication, may be required for $\mathrm{T}$ antigen-activated late gene expression in the absence of DNA replication (Brady and Khoury 1985; Keller and Alwine 1985). Given the complex, overlapping nature of these promoters and the large number of protein-DNA interactions that undoubtedly occur in this region, it is possible that activation of one promoter involves repression of the other. A possible bacterial paradigm is the bacteriophage $\lambda \mathrm{C}_{\mathrm{I}}$ repressor and cro genes, which are transcribed from divergent, overlapping promoters: Activation of $\mathrm{C}_{\mathrm{I}}$ transcription by repressor protein binding to the shared operator requires simultaneous repression of cro transcription (Ptashne 1986). In fact, recent evidence suggests that sequences in the SV40 early promoter, specifically, in the 21-bp repeats, are involved in repressing late SV40 expression before the onset of $\mathrm{T}$ antigen-mediated activation of the SV40 late promoter (Alwine and Picardi 1986).

How does DNA replication lead to activation of transcription from the adenovirus and SV40 late promoters in PSVAdL? One possibility is that changes in the chromatin structure of pSVAdL bring about an altered pattern of expression. Although the nature of such changes is unknown, two types of alterations in chromosome 
structure that may be induced by adenovirus DNA replication and may effect in part the early to late shift in adenovirus gene expression have been proposed (Thomas and Mathews 1980; Yu and Manley 1986). In addition, Cereghini and Yaniv (1984) demonstrated that replication-competent and -incompetent plasmids containing the SV40 regulatory region were rapidly assembled into chromatin following transfection, but that the nucleosome structure in the origin-promoter-enhancer region changed following replication.

The lack of a DNA replication requirement for both Ad2MLP and SV40 late expression in pSVAdL-transfected 293 cells was surprising. One trivial explanation for these findings was suggested by the results of Alwine (1985). He presented evidence that 293 cells retain and stabilize significantly higher quantities of transfected DNA than other cell types and suggested that the observed high levels of expression in these cells could result from high template copy number. However, we (Fig. 3 and unpubl. results), as well as others (Lebkowski et al. 1985; Grinnel et al. 1986), have observed, at most, only slightly elevated levels of DNA in this cell line (less than twofold in our hands). In addition, J. Alwine (pers. comm.) has tested a number of sublines of 293 cells and found that the ability of these cells to retain transfected DNA is subline specific and that the 293 cells used in these experiments did not retain high concentrations of transfected DNA.

Previous studies have noted differences in the requirements for obtaining gene expression in 293 cells, perhaps reflecting the presence of adenovirus Ela gene products in these cells. Most relevant, the Ad2MLP in p $\phi 4-S V A$ requires an enhancer for activity in HeLa cells, but functions totally independently of such an element in 293 cells (Lewis and Manley 1985a). This situation is strikingly analogous to the requirement in HeLa cells, but not 293 cells, for an origin of DNA replication to obtain expression from the Ad2MLP in pSVAdL. Indeed, our results show that the SV40 origin satisfies the operating definition of an enhancer: It is able to activate expression of a linked gene independent of its position in the plasmid. Furthermore, the origin of replication-induced enhancement shows both cell-type and promoter specificities, common features of enhancers (Khoury and Gruss 1983). These properties are consistent with the possibility that both elements may activate transcription by related mechanisms. For example, it may be that both an enhancer and DNA replication facilitate stable binding of transcription factors to certain promoter sequences. The relevant factors in 293 cells may be qualitatively or quantitatively different, so that stable binding occurs without the aid of additional elements. Interestingly, transcription from both the TATA boxcontaining Ad2MLP and the TATA box-lacking SV40 promoter was enhanced in 293 cells.

It is of interest to compare the effects that DNA replication in HeLa, 293, or COS-7 cells can exert on transcription from different promoters in transient expression assays. Human $\alpha$-globin, but not $\beta$-globin, expression was found to be stimulated on replicating plasmids in COS cells (Treisman et al. 1983). Expression of the SV40 early promoter was not significantly affected by DNA replication in HeLa cells, but was repressed by it in 293 cells (Lewis and Manley 1985b; Lebkowski et al. 1985). In contrast, the overlapping Ad2MLP-SV40 late promoters in pSVAdL absolutely required DNA replication for activity in HeLa cells, but were independent of it in 293 cells. The adenovirus pIX promoter appears to absolutely require DNA replication in HeLa cell transient expression assays (Matsue et al. 1986). Finally, expression from the isolated Ad2MLP was stimulated only slightly by replication in both HeLa and 293 cells. These results indicate that the effect of DNA replication on transcription can be much more profound than simply to increase template copy number. Rather, it appears that both cis- and trans-acting factors can determine the response of a given promoter to DNA replication.

\section{Materials and methods}

\section{Plasmids}

pSVAdL, which was described previously /Grass and Manley 1986), was constructed by inserting a fragment of adenovirus 2 (Ad2) DNA (Hu and Manley 1981) containing the Ad2MLP sequences from -66 to +33 with respect to the transcription initiation site into the KpnI restriction site (SV40 nucleotide 294) of the plasmid pSVRI, which contains the entire SV40 genome (Chen et al. 1983). The viral sequences were then recloned into the BamHI site of pBR322 by standard techniques. PSV3 contains wild-type SV40 DNA inserted in the BamHI site of pBR322.

A 3-bp deletion (nucleotides 5235-5237) at the origin-defining BglI site of pSVAdL was made to form pSVAdLori- ${ }^{-}$. Specifically, pSVAdL viral sequences were released from the plasmid by digestion with BamHI. The viral DNA was circularized by treatment with T4 DNA ligase and then relinearized by incubation with BglI. After treatment with the Klenow fragment of DNA polymerase I to render the BglI ends blunt, and with ligase to circularize the DNA, the molecules were linearized a third time, with BamHI, and inserted into the BamHI site of pBR322. The DNA sequence at the origin was determined by DNA sequencing (Maxam and Gilbert 1980). pSVAdL' and pSVAdLori ${ }^{-'}$ were constructed by liberating the viral sequences from pSVAdL and pSVAdLori ${ }^{-}$with BamHI and inserting them into the BamHI site of pSVOd, which contains a functional SV40 replication origin (Mellon et al. 1981). All plasmids are shown schematically in Figure 1.

$\mathrm{p} \phi \mathrm{SaLB}$ was constructed from p $\phi 4$ SVA (see Fig. 1), which contains adenoviral sequences from -405 to +33 , relative to the major late transcriptional start site, attached to SV40 sequences extending from a HindIII site at nucleotide 5171 to the BamHI site at nucleotide 2533 (Lewis and Manley 1985a). The SV40 DNA includes the early coding sequences and polyadenylation signal, but no promoter or $\mathrm{T}$ antigen binding sites. A fragment of pSVAdL containing the origin of DNA replication as well as the enhancer region (SV40 nucleotide 294-5171) was liberated from pSVAdL by digestion with EcoRI and HindIII, treated with the Klenow fragment to render its ends blunt, and ligated into $\mathrm{p} \phi \mathrm{SVA}$ at the Klenow-treated SalI site to produce p $\phi 4$ SaLB. $p \phi 4 S V A e$, which contains the SV40 enhancer region but no replication origin (Fig. 1), was described previously (Lewis and Manley 1985a). 


\section{Cells and transfection}

HeLa, 293, and COS-7 cells were grown in Dulbecco's modified Eagle medium with $10 \%$ fetal bovine serum (GIBCO). HeLa and 293 transfections were performed by the calcium phosphate precipitate method (Wigler et al. 1979), as described previously (Lewis and Manley 1985a). Transfection of COS-7 cells was performed using DEAE-dextran (Pharmacia Fine Chemicals) (McCutchan and Pagano 1968). Briefly, COS-7 cells were plated at a density of $3 \times 10^{6}$ cells $/ 150-\mathrm{mm}$ dish. Three micrograms of DNA was left on the cells for $30 \mathrm{~min}$ at $37^{\circ} \mathrm{C}$ in $0.5 \mathrm{mg} / \mathrm{ml}$ DEAE-dextran, $1 \times$ DME, during which time the cells were rocked every $5 \mathrm{~min}$. After the transfection mixture was removed, the cells were washed with DME and incubated in DME- $5 \%$ fetal calf serum $-100 \mu \mathrm{M}$ chloroquine for $6-8 \mathrm{hr}$ (Levitt et al. 1985). The cells were then washed twice with DME and incubated in DME-5\% fetal calf serum for 40-48 hr. Transfections were performed on multiple occasions to control for possible variability.

\section{RNA extraction and analysis}

Cytoplasmic RNA was extracted from HeLa, 293, and COS-7 cells $48 \mathrm{hr}$ post-transfection as described previously (Grass and Manley 1986). Nuclease S1 analysis (Berk and Sharp 1978) was performed using either a single-stranded BstNI fragment of pSVAdL (SV40 nucleotides 358-232) or a single-stranded SV40 DdeI fragment (SV40 nucleotides 287-5228) as described previously (Grass and Manley 1986). DNA fragments were 5 '-endlabeled with T4 polynucleotide kinase and $\left[\gamma^{-32} \mathrm{P}\right]$ ATP. Primer extension analysis was performed as described by McKnight and Kingsbury (1982). The primer spanned SV40 nucleotides 5131-5094 and was 5 '-end-labeled (5094) with $\left[\gamma^{-32}\right.$ P]ATP and T4 polynucleotide kinase. Products of both S1 nuclease digestion and primer extension were analyzed by electrophoresis through $5 \%$ polyacrylamide $-8 \mathrm{M}$ urea gels (Maxam and Gilbert 1980).

\section{Indirect immunofluorescence}

Indirect immunofluorescence was carried out as described previously (Verderame et al. 1980; Lewis and Manley 1985a) on cells isolated $40-48 \mathrm{hr}$ post-transfection. Anti-T-antigen monoclonal antibody PAb416 (Crawford et al. 1982) was used to detect the SV40 large T antigen.

\section{DNA replication assays}

Low-molecular-weight DNA was isolated from HeLa and 293 cell nuclei $48 \mathrm{hr}$ post-transfection by a modification of the Hirt extraction procedure (Hirt 1967). Nuclei isolated as described previously (Grass and Manley 1986) were resuspended in $10 \mathrm{mM}$ Tris- $\mathrm{HCl}(\mathrm{pH} 7.5), 10 \mathrm{~mm}$ EDTA, and transferred to microfuge tubes. Twenty percent SDS was added with gentle mixing to a final concentration of $0.6 \%$. Following a $15-\mathrm{min}$ incubation at room temperature, $\mathrm{NaCl}$ was added dropwise to a final concentration of $0.9 \mathrm{M}$, and the mixture was left overnight on ice. High-molecular-weight DNA was removed by centrifugation for $20 \mathrm{~min}$, and the resulting supernatant was extracted with phenol-chloroform prior to ethanol precipitation.

Five percent of the low-molecular-weight DNA isolated in this way was digested overnight with either $D p n I$ or $M b o I$ and then treated with SalI to linearize the resistant fractions. The digestion products were resolved on a $1 \%$ agarose gel and transfered to nitrocellulose filters (Southern 1975). The blots were probed with a nick-translated NaeI-EcoRI SV40 late region fragment. Autoradiographic exposure was made without an intensifying screen.

\section{Acknowledgments}

We thank W. Ehrman and M. Kopczynski for excellent technical assistance. This work was supported by grants CA 33620 and GM 28983 from the National Institutes of Health.

\section{References}

Aiello, L., R. Guilfoyle, K. Huebner, and R. Weinmann. 1979. Adenovirus 5 DNA sequences present and RNA sequences transcribed in transformed human embryo kidney cells (HEK-Ad-5 or 293). Virology. 94: 460-469.

Alwine, J.C. 1985. Transient gene expression control: Effects of transfected DNA stability and trans-activation by viral early proteins. Mol. Cell. Biol. 5: 1034-1042.

Alwine, J.C. and J. Picardi. 1986. Activity of simian virus 40 late promoter elements in the absence of large $\mathrm{T}$ antigen: Evidence for repression of late gene expression. $I$. Virol. 60: 400-404.

Berk, A.J. and P.A. Sharp. 1978. Spliced early mRNAs of simian virus 40. Proc. Natl. Acad. Sci. 75: 1274-1278.

Brady, J. and G. Khoury. 1985. Trans-activation of simian virus 40 late transcription unit by T-antigen. Mol. Cell. Biol. 5: $1391-1399$.

Brady, J., J.B. Bolen, M. Radonovich, N. Salzman, and G. Khoury. 1984a. Stimulation of simian virus 40 late gene expression by simian virus $40 \mathrm{~T}$ antigen. Proc. Natl. Acad. Sci. 81: 2040-2044.

Brady, J., M. Radonovich, M. Thoren, G. Das, and N.P. Salzman. 1984b. Simian virus 40 major late promoter: An upstream DNA sequence required for efficient in vitro transcription. Mol. Cell. Biol. 4: 133-141.

Carthew, R.W., L.A. Chadosh, and P.A. Sharp. 1985. An RNA polymerase II transcription factor binds to an upstream element in the adenovirus major late promoter. Cell 43: 439448.

Cereghini, S. and M. Yaniv. 1984. Assembly of transfected DNA into chromatin: Structural changes in the origin-promoter enhancer region upon replication. EMBO I. 3: 12431253.

Chen, S., D.S. Grass, G. Blanck, N. Hogansen, J.L. Manley, and R.E. Pollack. 1983. A functional simian virus 40 origin of replication is required for the generation of a super $\mathrm{T}$ antigen with a molecular weight of 100,000 in transformed mouse cells. J. Virol. 48: 492-502.

Crawford, L., K. Leppard, D. Lane, and E. Harlow. 1982. Cellular proteins reactive with monoclonal antibodies directed against simian virus $40 \mathrm{~T}$ antigen. J. Virol. 42: 612-620.

Davison, B.L., J.-M. Egly, E.R. Mulvihill, and P. Chambon. 1983. Formation of stable preinitiation complexes between class $\mathrm{B}$ transcription factors and promoter sequences. $\mathrm{Na}$ ture 301: 680-686.

Dynan, W.S. and R. Tjian. 1983. The promoter specific transcription factor spl binds to upstream sequences in the SV40 early promoter. Cell 35: 79-87.

Fried, M. and C. Prives. 1986. The biology of simian virus 40 and polyoma virus. In Cancer cells, vol. 4, (ed. M. Botchan, T. Grodzicker, and P.A. Sharpl, pp. 1-16. Cold Spring Harbor Laboratory, Cold Spring Harbor, New York.

Fromm, M. and P. Berg. 1982. Deletion mapping of DNA regions required for SV40 early promoter function in vivo. $J$. Mol. Appl. Genet. 1: 457-481. 
Gidoni, D., J.T. Kadonaga, H. Barrera-Saldana, K. Takahashi, P. Chambon, and R. Tiian. 1985. Bi-directional SV40 transcription mediated by tandem Spl binding interactions. Science 230: $511-517$.

Gluzman, Y. 1981. SV40-transformed simian cells support replication of early SV40 mutants. Cell 23: 175-182.

Graham, F.L., J. Smiley, W.C. Russell, and R. Nairn. 1977. Characteristics of a human cell line transformed by DNA from human adenovirus type 5. J. Gen. Virol. 36: 59-72.

Grass, D.S. and J.L. Manley. 1986. Effects of the adenovirus 2 late promoter on simian virus 40 transcription and replication. J. Virol. 57: 129-137.

Grinnell, B.W., D.T. Berg, and J. Walls. 1986. Activation of the adenovirus and BK virus late promoters, effects of the BK virus enhancer and trans-acting viral early proteins. Mol. Cell. Biol. 6: 3596-3605.

Hansen, U. and P.A. Sharp. 1983. Sequences controlling in vitro transcription of SV40 promoters. EMBO I. 2: 2293-2304.

Hartzell, S.W., B.J. Byrne, and K.N. Subramanian. 1984a. Mapping of the late promoter of simian virus 40 . Proc. Natl. Acad. Sci. 81: 7132-7136.

- 1984b. The simian virus 40 minimal origin and the 72 base-pair repeat are required simultaneously for efficient induction of late gene expression with large tumor antigen. Proc. Natl. Acad. Sci. 81: 6335-6339.

Hen, R., P. Sassone-Corsi, J. Corden, M.P. Gaub, and P. Chambon. 1982. Sequences upstream from the TATA box are required in vivo and in vitro for efficient transcription from the adenovirus serotype 2 major late promoter. Proc. Natl. Acad. Sci. 79: 7132-7136.

Hirt, B. 1967. Selective extraction of polyoma DNA from infected mouse cell cultures. J. Mol. Biol. 26: 365-369.

$\mathrm{Hu}$, S.-L. and J. Manley. 1981. DNA sequences required for initiation of transcription in vitro from the major late promoter of adenovirus 2. Proc. Natl. Acad. Sci. 78: 820-824.

Keller, J.M. and J.C. Alwine. 1984. Activation of the SV40 late promoter: Direct effects of $\mathrm{T}$ antigen in the absence of viral DNA replication. Cell 36: 381-389.

- 1985. Analysis of an activatable promoter sequence in the simian virus 40 late promoter required for $\mathrm{T}$ antigen mediated trans activation. Mol. Cell. Biol. 5: 1859-1869.

Khoury, G. and P. Gruss. 1983. Enhancer elements. Cell 33: $313-314$.

Lebkowski, J.S., S. Clancy, and M.P. Calos. 1985. Simian virus 40 replication in adenovirus-transformed human cells antagonizes gene expression. Nature 317: 169-171.

Levitt, A., S. Chen, G. Blanck, D. George, and R.E. Pollack. 1985. Two integrated partial repeats of simian virus 40 together code for a super-T antigen. Mol. Cell. Biol. 5: 742750.

Lewis, E.D. and J.L. Manley. 1985a. Control of adenovirus late promoter expression in two human cell lines. Mol. Cell. Biol. 5: 2433-2442.

1985b. Repression of SV40 early transcription by viral DNA replication in human 293 cells. Nature 317: 172-175.

Matsui, T., M. Murayama, and T. Mita. 1986. Adenovirus 2 peptide IX gene is expressed only on replicated DNA molecules. Mol. Cell. Biol. 6: 4149-4154.

Maxam, A.M. and W. Gilbert. 1980. Sequencing end-labeled DNA with base- specific chemical cleavages. Methods Enzymol. 65: 499-561.

McCutchen, J.H. and J.S. Pagano. 1968. Enhancement of the infectivity of simian virus 40 deoxyribonucleic acid with diethylaminoethyl-dextran. J. Natl. Cancer Inst. 41: 351357.
McKnight, S. and R. Kingsburg. 1982. Transcriptional control signals of a eukaryotic protein-coding gene. Science 217: 316-324.

McKnight, S. and R. Tjian. 1986. Transcriptional selectivity of viral genes in mammalian cells. Cell 46: 795-805.

Mellon, P., V. Parker, Y. Gluzman, and T. Maniatis. 1981. Identification of DNA sequences required for transcription of the human al-globin gene in a new SV40 host-vector system. Cell 27: 279-288.

Mishoe, H., J.N. Brady, M. Radonovich, and N.P. Salzman. 1984. Simian virus 40 guanine-cytosine-rich sequences function as independent transcriptional control element in vitro. Mol. Cell. Biol. 4: 2911-2920.

Moreau, P., R. Hen, B. Wasylyk, R. Everett, M.B. Gaub, and P. Chambon. 1981. The SV40 72 base pair repeat has a striking effect on gene expression both in SV40 and other chimeric recombinants. Nucleic Acids Res. 9: 6047-6067.

Ptashne, M. 1986. Gene regulation by proteins acting nearby and at a distance. Nature 322: 697-701.

Robbins, P.D., D.C. Rio, and M.R. Botchan. 1986. Trans-activation of the simian virus 40 enhancer. Mol. Cell. Biol. 6: $1283-1295$.

Sawadogo, M. and R.G. Roeder. 1985. Interaction of a gene-specific transcription factor with the adenovirus major late promoter upstream of the TATA box region. Cell 43: 165-175.

Southern, E.M. 1975. Detection of specific sequences among DNA fragments separated by gel electrophoresis. $J$. Mol. Biol. 98: 503-517.

Thomas, G.P. and M.B. Mathews. 1980. DNA replication and the early to late transition in adenovirus infection. Cell 22: 523-533.

Tooze, J. (ed.) 1981. DNA tumor viruses, 2nd edition. Cold Spring Harbor Laboratory, Cold Spring Harbor, New York

Treisman, R., M.R. Green, and T. Maniatis. 1983. Cis and trans activation of globin gene transcription in transient assays. Proc. Natl. Acad. Sci. 80: 7428-7432.

Verderame, M., D. Alcorta, M. Egnor, K. Smith, and R. Pollack. 1980. Cytoskeletal F-actin patterns quantitated with fluorescein isothiocyanate-phalloidin in normal and transformed cells. Proc. Natl. Acad. Sci. 77: 6624-6628.

Wigler, M., A. Pellicer, S. Silverstein, R. Axel, G. Urlaub, and L. Chasin. 1979. DNA-mediated transfer of the adenine phosphoribosyltransferase locus into mammalian cells. Proc. Natl. Acad. Sci. 76: 1373-1376.

Yu, Y.-T. and J.L. Manley. 1986. Structure and function of the S1 nuclease-sensitive site in the adenovirus late promoter. Cell 45: 743-751. 


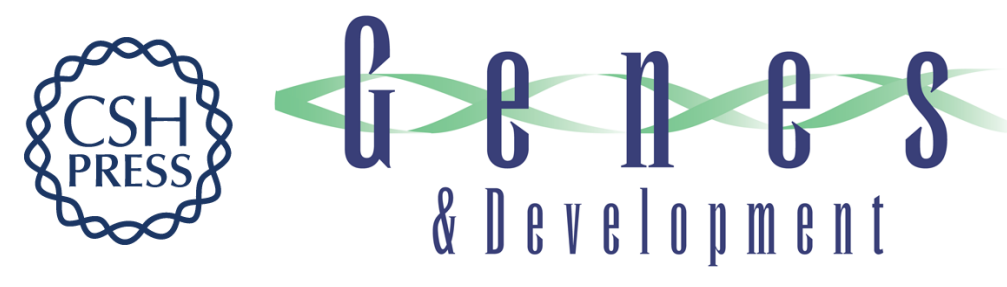

\section{Cell- and promoter-specific activation of transcription by DNA replication.}

D S Grass, D Read, E D Lewis, et al.

Genes Dev. 1987, 1:

Access the most recent version at doi:10.1101/gad.1.10.1065

References This article cites 49 articles, 25 of which can be accessed free at: http://genesdev.cshlp.org/content/1/10/1065.full.html\#ref-list-1

License

Email Alerting

Receive free email alerts when new articles cite this article - sign up in the box at the top Service right corner of the article or click here.

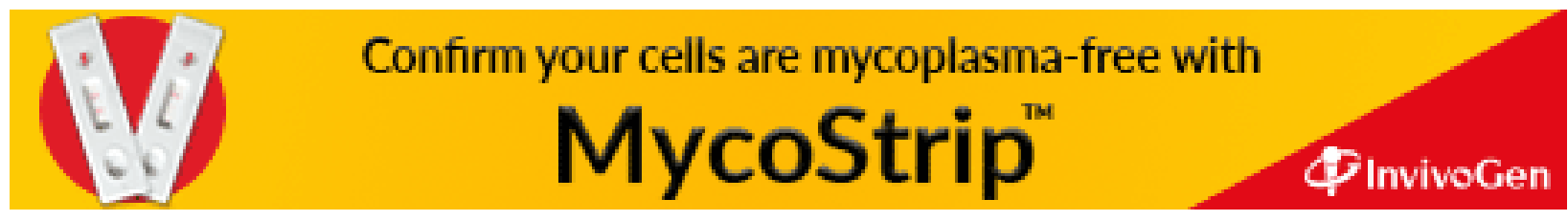

